\title{
EXPERIMENTAL STUDY TO DETERMINE THE LOCAL CONDENSATION HEAT TRANSFER COEFFICIENTE FOR R134A FLOWING THROUGH A 4.8 MM INTERNAL DIAMETER SMOOTH HORIZONTAL TUBE
}

\author{
R. P. Mendes ${ }^{\mathrm{a}}$, \\ D. L. Pottie ${ }^{a}$ \\ C. H. Paula ${ }^{\text {a }}$ \\ J. G. Pabon \\ L. Machado ${ }^{a}$ \\ ${ }^{a}$ Programa de Pós Graduação da Universidade \\ Federal de Minas Gerais \\ Departament of Mechanical Enginnering \\ Bairro Pampulha \\ CEP. 31270-901, Belo Horizonte, Minas \\ Gerais, Brasil \\ ramondepaoli@yahoo.com.br \\ bUniversidade Federal de Itajubá, \\ Departament of Mechanical Enginnering \\ Av.B.P.S, 1303 \\ Bairro Pinheirinho \\ CEP.37500-015 \\ Itajubá, Minas Gerais, Brazil. \\ Received: Apr 14, 2020 \\ Revised: Aug 06, 2020 \\ Accepted: Feb 17, 2021
}

\section{ABSTRACT}

Refrigerant fluid R134a is commonly one of the most utilised in vapour compression cycles wordlide, wheter in dommestic HVAC or automotive regrigeration systems. This paper's goal is to experimetnally determine the fluid local condensation Heat Transfer Coefficient (HTC), in several flor regimes. In this work, the mass flux was equal to 200,250 and $300 \mathrm{~kg}\left(\mathrm{~m}^{2} \mathrm{~s}\right)^{-1}$ and the fluid flowed through a smooth, horizontal $4.8 \mathrm{~mm}$ internal diameter aluminium pipe, during which its vapour quality varied along the entire quality range. A purpose built test rig was developed, in which fluid conditions were constantly monitored and controlled. Through measurements in temperature and pressure, an energy balance was used to calculate experimentally the local heat transfer coeeficient. Average results for the unit quality range equalled to 3781,3459 and $3944 \mathrm{~W} \cdot\left(\mathrm{m}^{2} \cdot \mathrm{K}\right)^{-1}$ for saturation temperature equal to $30^{\circ} \mathrm{C}$ and the aforementioned mass velocities. Likewise, at $35^{\circ} \mathrm{C}$ the averages HTC found were 2903, 3141 and $3898 W\left(\mathrm{~m}^{2} \mathrm{~K}\right)^{-1}$ at the same mass flux rates. Later on, the experimental results were compared to ten commonly used HTC correlation found in relevant references, with Chato's correlation returning the best fitting.

Keywords: condensation, R134a, heat transfer coefficient, experimental work

\section{NOMENCLATURE}

$\begin{array}{ll}\text { D } & \text { Diameter } \\ \text { G } & \text { Mass flux } \\ \text { G } & \text { Gravitational acceleration } \\ \text { i } & \text { Enthalpy } \\ \text { I } & \text { Electrical current } \\ \text { L } & \text { Length } \\ \dot{Q} & \text { Heat rate } \\ \text { q" } & \text { Heat flux } \\ \text { L } & \text { Length } \\ \text { P } & \text { Pressure } \\ \text { X } & \text { Vapor Quality } \\ \text { pr } & \text { Reduction pressure } \\ \mathrm{k} & \text { Conductivity } \\ \text { pr } & \text { Reduction pressure } \\ \text { T } & \text { Saturation temperature } \\ \text { HTC } & \text { Heat transfer coefficient } \\ \text { TPI } & \text { Internal wall temperature } \\ \text { PDO } & \text { Ozone degradation potential } \\ \text { GWP } & \text { Global Warming Potential }\end{array}$

\author{
Greek Symbols \\ Angle subtended from the top of tube to the liquid \\ Efficiency [-] \\ Density \\ Dynamic viscosity \\ Diference of Temperature between Tsat and TPI \\ Haragushi parameter \\ Superficial Tension \\ Subcripts \\ lg Difference between liquid and vapor
}

exp Experimental

e Inlet

L Liquid

lo Only liquid in the tube

out Outlet

Pred Predicted

g Vapor 


\section{INTRODUCTION}

The refrigerant fluid R134a is a main substitute to the R12, which was formerly used in refrigeration systems worldwide. Due to its low toxicity, no flammability, high thermal and chemical stability and suitable to be used with many materials, this fluid presents widespread application in HVAC, industrial chillers and commercial refrigeration. While the lack of chlorine in its composition results in zero Ozone Depletion Potential (ODP), R134a Global Warming Potential is considerably elevated, figuring around $1300\left(\mathrm{CO}_{2}\right.$ is the reference, with GWP 1$)$. This fact is mainly due to the ability to resonate and reflect radiation incoming from the planter surface. This means that while from the ODP point of view this fluid is a major step forward, further research in fluid development is clearly justified. However, since this recent development has yet to reach commercial levels, R134a is still one of the most used fluids worldwide, and so, must be subject to further research and development whose aim is to ensure effective and efficient operation.

In its study, Berrada (1996) studied the R134a condensation Heat Transfer Coefficient (HTC) in smooth flat tube, with an internal diameter of $8.92 \mathrm{~mm}$ over a wide range of conditions: mass velocities varying between 89 and $432 \mathrm{~kg}\left(\mathrm{~m}^{2} \mathrm{~s}\right)^{-1}$, saturation temperatures between 40 and $47^{\circ} \mathrm{C}$ and vapour quality between 19 and 70\%. This study concluded that R134a presents smaller HTC varying between 1 and $4 \mathrm{~kW}\left(\mathrm{~m}^{2} \mathrm{~K}\right)^{-1}$, values smaller than encountered to R22 under similar conditions. Likewise, Sapalli (2009) investigated the R134a condensation HTC in similar size tubes, but over a wider temperature and mass flux windows, 35 to $60^{\circ} \mathrm{C}$ and 90 to $800 \mathrm{~kg}\left(\mathrm{~m}^{2} \mathrm{~s}\right)^{-1}$ respectively. In this study, 560 experimental operating points were obtained, and the HTC values ranged from 1 and $7.2 \mathrm{~kW}\left(\mathrm{~m}^{2} \mathrm{~K}\right)^{-1}$.

In this paper, an experimental prototype was built to investigate the R134a condensation Heat Transfer Coefficient flowing through a smooth, horizontal copper pipping with an internal diameter of $4.8 \mathrm{~mm}$. Here, the mass flux will be set at three values $\left(200,250\right.$ and $\left.300 \mathrm{~kg}\left(\mathrm{~m}^{2} \mathrm{~s}\right)^{-1}\right)$ and the saturation temperature equal to 30 and $35^{\circ} \mathrm{C}$, over the entire unit quality range. In the following sections, the experimental setup will be presented, the test procedure explained, the results presented and duly discussed. These results will be compared to references found in the literature.

\section{EXPERIMENTAL SETUP}

The experimental setup build in this project was used to obtain measurements that allowed the calculation of the condensation HTC across the condenser length. The R134a fluid flows in a controlled manner, and through measurements at the condenser inlet and heating section, the fluid quality could be precisely determined.

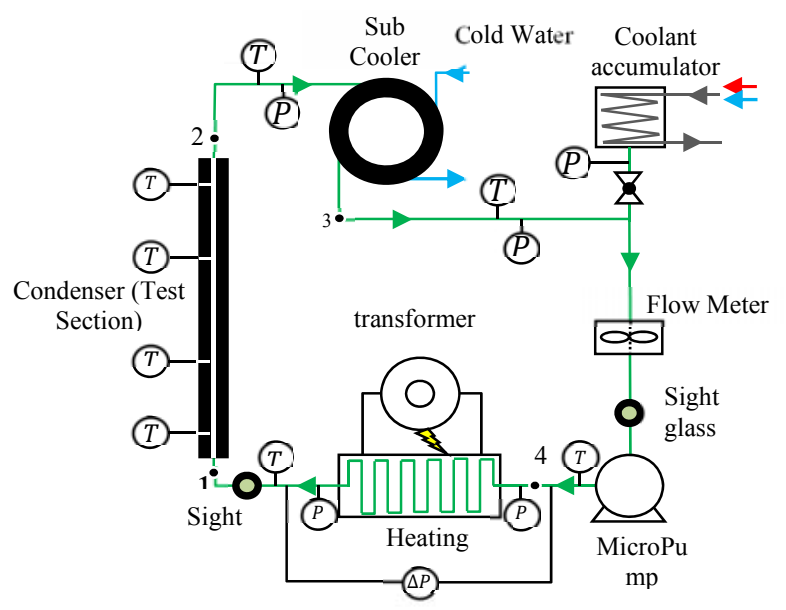

T: Thermocouples; P: Pressure Transducers

Figure 1. Schematic representation of the built experimental setup

The micro-pump, model GJ-N23 manufactured by Micropump (2016), pumps the fluid in the system, through a $4.8 \mathrm{~mm}$ internal diameter copper pipping towards the heating section, which is comprised of an electrical resistor wound around a similar copper pipping, and insulated from the surroundings in thick rockwool. In this heating section, which is analogous to an evaporator in common refrigeration cycles, the fluid changes phase, going from liquid to vapour. The rate of phase change is controlled by managing the heat dissipation in the electrical resistance through a variable autotransformer. At the inlet and outlet (4 and 1, respectively), temperature and pressure are measured, and at the outlet, a sight glass is installed to visually inspect the flow conditions.

After leaving the test rig heating section, the now two-phase fluid flow enters the test section. It is consisted of a concentric tube counter current heat exchanger, in which the R134a flows through the inner tube, and the outer uses cold water to remove energy from the refrigerant. This way, as the refrigerant flows through the test section, it condensates. Thermocouples are installed at the water inlet and outlet, as well as along the inner tube external wall. This way, temperatures are used to determine heat flows. Further details about the test section will be given ahead, in further sections of this paper.

Upon leaving the test section, the refrigerant fluid enters the subcooler, whose function is to ensure complete condensation, followed by a fluid divergence valve. In this valve, fluid can either continue flowing through the test rig, or be directed to an accumulator, changing the total fluid mass in the system. This is only used when setting experiments up, and not during regular test operation. Following this divergence, the 
$\mathrm{R} 134 \mathrm{a}$ flow rate is measured at the mass flux meter, a turbine type Kobold, another sight glass to finally return to the micropump, closing the loop and restarting operation. Following, in tab. (1) a summary of the components instruments is presented.

Table 1. Summary of the components

\begin{tabular}{|l|l|l|c|}
\hline Sym. & \multicolumn{1}{|c|}{ Name } & \multicolumn{1}{c|}{ Description } & Accuracy \\
\hline $\mathrm{T}$ & Thermocuple & Type T & \pm 0.35 \\
\hline $\mathrm{P}$ & $\begin{array}{l}\text { Pressure } \\
\text { Transduter }\end{array}$ & $\begin{array}{l}\text { Out signal 4 - } \\
20 \mathrm{~mA}\end{array}$ & $\pm 2 \mathrm{kPa}$ \\
\hline $\mathrm{MP}$ & Micro pump & GJ-N23 & $\mathrm{N} / \mathrm{A}$ \\
\hline$\Delta \mathrm{P}$ & $\begin{array}{l}\text { Differential } \\
\text { Pressure }\end{array}$ & Rosemount & $2 \mathrm{kPa}$ \\
\hline FM & Flow meter & Kobold Model & $\pm 1.5 \% \mathrm{FS}$ \\
\hline $\mathrm{W}$ & Power meter & (osciloscopio) & $\pm 3 \% \mathrm{RD}$ \\
\hline
\end{tabular}

The acquired experimental data and each instrument accuracy was considered to calculate the expanded uncertainty for indirect measurements and calculated variables, namely mass velocity, vapour quality and HTC through Taylor \& Kuavatt (1997) proposed methodology. The instruments signal output was read through an NI USB 6211 module and a Labview test platform, specifically built to interpret signal incoming from the test rig. The data was then exported to Engineering Equation Solver (EES) software

\section{MATHEMATICAL MODEL}

In this section, each component will be modelled by applying mathematical correlations and equations to describe their physical behaviour.

\section{Heating section}

The heating section function is equivalent to the evaporator in a regular heat pump system. At the inlet, the fluid enters as a single-phase liquid, either saturated or compressed, absorb the heat output from an electric resistor and leaves as a two-phase saturated mixture. By measuring the temperature and pressure at the inlet and outlet, as well as the electric power dissipation, the energy balance can be applied to determine the outlet vapour quality. Firstly, considering that the power dissipated from the electric resistor - i.e., the product between voltage applied and electric current $\dot{Q}=\mathrm{VI}-$ is absorbed by the fluid, decreased by an efficiency factor, it is possible to determine

$$
\dot{\mathrm{Q}}=\eta \mathrm{VI}=\dot{\mathrm{m}}_{\mathrm{R} 134 \mathrm{a}}\left(\mathrm{h}_{\mathrm{e}}-\mathrm{h}_{\ell}-\mathrm{xh}_{\ell \mathrm{g}}\right)
$$

In Equation (1), $\eta$ is the electric to refrigerant heat transfer efficiency, estimated by the authors based on temperature measurements outside the thermal insulator as equal to $0.97 . \mathrm{V}$ and I are the electric voltage and current, measured in volts and ampere respectively. $\dot{\mathrm{m}}_{\mathrm{R} 134 \mathrm{a}}$ is the refrigerant mass flux, measured at the mass flux meter given in $\mathrm{kg} \mathrm{s}^{-1}$, the specific enthalpy $\left(h_{e}\right)$ the fluid inlet state, $h_{\ell}$ is the saturated liquid specific enthalpy and $h_{\ell g}$ the phase change specific enthalpy all given in $\mathrm{kJ} \mathrm{kg}^{-1}$ and $\mathrm{x}$ is the dimensionless vapour quality. By rearranging Eq. (1) it is possible to express the outlet quality as a function of the remaining variables, which are either read or calculated, and so, determine the vapour mixture that flows to the next component of the test rig: the test section

$$
\mathrm{x}_{\mathrm{in}}=\frac{\left[\frac{\eta \mathrm{VI}}{\mathrm{m}_{\mathrm{R} 134 \mathrm{a}}}\right]-\left(\mathrm{h}_{\ell}+\mathrm{h}_{\mathrm{e}}\right)}{\mathrm{h}_{\ell \mathrm{g}}}
$$

Lastly, aiming to confirm the validity of Equations (1) and (2), the authors forced a single-phase liquid to flow in the entire heating section. This way, by measuring the temperature difference in the liquid only flow, the enthalpy difference can be simplified to $\Delta \mathrm{h}^{\Delta \mathrm{T}}=\mathrm{c}_{\mathrm{p}} \Delta \mathrm{T}$, and use this to indirectly calculate the mass flux and heat exchange efficiency, confirming the data acquired.

\section{Test section}

The test section is the principal component of the test rig. It consists of a concentric tube heat exchanger, in which the refrigerant fluid flows through the inner tube and condensates, releasing latent heat which is absorbed as sensible heat by water flowing in a counter current setup in the outer tube. A cross section view of the test section is presented in Fig. (2).

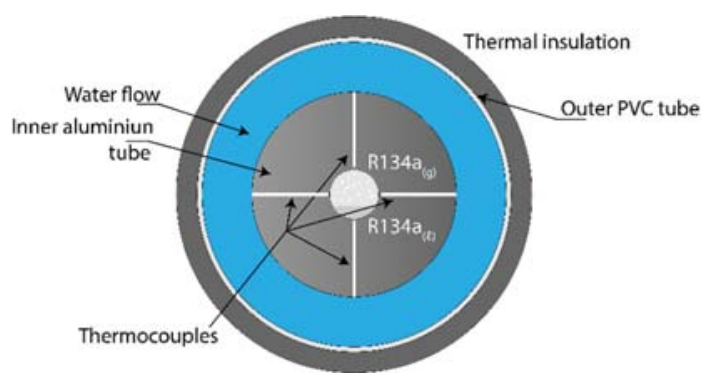

Figure 2. Test section cross view

The test section was built with a custom-made aluminium tube with inner and outer diameters of 4.8 and $75 \mathrm{~mm}$, respectively. This large thermal mass is to ensure thermal stability during the duration of tests, but as a drawback, required a long time to reach thermal steady state conditions. The total test section length is $1 \mathrm{~m}$ and after $120 \mathrm{~mm}$ from each end, and spaced $250 \mathrm{~mm}$ in between, four thermocouples were installed in holes drilled in the aluminium tube touching the inside tube wall, and located at each side top and bottom, as shown in Fig. (2) . In figure 3, a lengthwise schematic representation of the test section is shown. $\mathrm{AA}^{\prime}$ to $\mathrm{DD}^{\prime}$ are the locations in which 
thermocouples are installed. Outside the aluminium tube water flows in the opposite direction, through a $100 \mathrm{~mm}$ outside diameter PVC tube, which is thermally insulated from the surroundings. Water mass flux and temperature were measured on the inlet and outlet. Then, an energy balance is performed, and by neglecting thermal losses between the water and the surrounding due to the thermal insulation, it is possible to consider that the energy absorbed by the water is used to induce condensation in R134a. The heat transferred in each section is used to determine the local condensation Heat Transfer Coefficient.

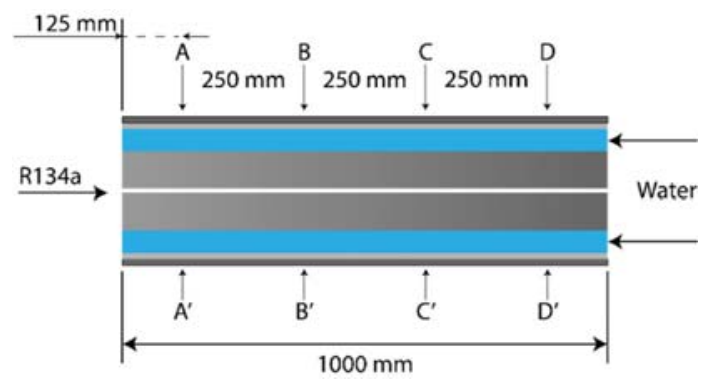

Figure 3. Test section schematic representation as

The heat absorbed by the water can be calculated

$$
\dot{\mathrm{Q}}_{\mathrm{w}}=\dot{\mathrm{m}}_{\mathrm{w}} \mathrm{c}_{\mathrm{p}_{\mathrm{w}}}\left(\mathrm{T}_{\mathrm{w}_{\text {out }}}-\mathrm{T}_{\mathrm{w}_{\mathrm{in}}}\right)
$$

In which $\mathrm{c}_{\mathrm{p}_{\mathrm{w}}}$ is the specific heat of liquid water, considered equal to $4180 \mathrm{~J}(\mathrm{~kg} \mathrm{~K})^{-1}, \mathrm{~T}_{\mathrm{w}_{\text {out }}}$ and $\mathrm{T}_{\mathrm{w}_{\text {in }}}$ are the water outlet and inlet temperature, in either $\mathrm{K}$ or ${ }^{\circ} \mathrm{C}$ and $\dot{\mathrm{m}}$ is the water mass flux rate, in $\mathrm{kg} \mathrm{s}^{-1}$, yielding thus $\dot{\mathrm{Q}}_{\mathrm{W}}$ in $\mathrm{W}$. By considering this thermal energy as released by the phase-change in R134a, it is possible to apply Newton's law of cooling

$$
\dot{\mathrm{Q}}_{\mathrm{w}}=\mathrm{h}_{\mathrm{f}} \mathrm{A}\left(\mathrm{T}_{\mathrm{sat}}-\mathrm{T}_{\mathrm{iw}}\right)
$$

in which $h_{f}$ is the convective heat transfer coefficient during condensation, expressed in $\mathrm{W}\left(\mathrm{m}^{2} \mathrm{~K}\right)^{-1}, \mathrm{~A}$ is the inner wall area, in $\mathrm{m}^{2}, \mathrm{~T}_{\text {sat }}$ is the saturation temperature (actual fluid temperature) and $\mathrm{T}_{\mathrm{iw}}$ is the internal wall temperature, taken as the four thermocouples average in each test cross section (AA' to DD'), all given in K. Combining equations (3) and (4) yield

$$
\mathrm{h}_{\mathrm{f}}=\frac{\dot{\mathrm{m}}_{\mathrm{w}} \mathrm{c}_{\mathrm{p}_{\mathrm{w}}}\left(\mathrm{T}_{\mathrm{w}_{\text {out }}}-\mathrm{T}_{\mathrm{w}_{\text {in }}}\right)}{\mathrm{A}\left(\mathrm{T}_{\text {sat }}-\mathrm{T}_{\mathrm{iw}}\right)}
$$

Considering the heat flux $\ddot{Q}$ as the ratio between total heat flow over the area $\left(\mathrm{W} \mathrm{m}^{-2}\right)$, Eq. (5) can be further simplified to

$$
\mathrm{h}_{\mathrm{f}}=\frac{\ddot{\mathrm{Q}}}{\left(\mathrm{T}_{\mathrm{sat}}-\mathrm{T}_{\mathrm{iw}}\right)}
$$

Now, considering every fourth $(250 \mathrm{~mm})$ of the test section, centred at the sections $\mathrm{AA}^{\prime}$ to $\mathrm{DD}$, to present constant heat transfer at the average thermocouple temperature, it is possible to determine the local convective HTC and quality variation between each said section and inlet condition, which are fully determined. This way, the vapour quality at a given section $\mathrm{XX}^{\prime}$

$$
\mathrm{X}_{\mathrm{XX}} \mathrm{X}_{\mathrm{in}}-\frac{\ddot{\mathrm{Q}} \pi \mathrm{d}_{\mathrm{in}} \mathrm{L}_{\mathrm{in} \rightarrow \mathrm{XX}}}{\dot{\mathrm{m}}_{\mathrm{R} 134 \mathrm{a}} \mathrm{h}_{\ell \mathrm{g}}}
$$

The set of equations (1) through (7) are then used to experimentally determine the local convection condensation Heat Transfer Coefficient under different flow regimes, summarised in Tab. (2).

Table 2. Operation conditions studied in this paper

\begin{tabular}{|c|c|c|c|}
\hline $\mathrm{T}_{\mathrm{sat}}\left({ }^{\circ} \mathrm{C}\right)$ & $\mathrm{T}_{\mathrm{W}}\left({ }^{\circ} \mathrm{C}\right)$ & $\mathrm{G}\left(\mathrm{kg}\left(\mathrm{m}^{2} \mathrm{~s}\right)^{-1}\right)$ & $\mathrm{x}_{\mathrm{in}}$ \\
\hline $30 \& 35$ & $20 \& 25$ & $200 ; 250 \& 300$ & $\begin{array}{l}10 \% \\
\rightarrow 100 \%\end{array}$ \\
\hline
\end{tabular}

\section{HEAT TRANSFER COEFFICIENT - LITERATURE CORRELATIONS}

In order to confirm the validity of the experimental results and mathematical model developed, they were compared to ten consolidated HTC literature correlations. These are: Shah (2016), Cavallini (1974), Chato (1998), Haragushi (1994), Aker (1960. ), Bohdal (2011), Park (2011), Wang (2002), Huang (2010) and Koyama (2003), as follows:

Table 3 - Heat Transfer Coefficient by Condensation Correlations

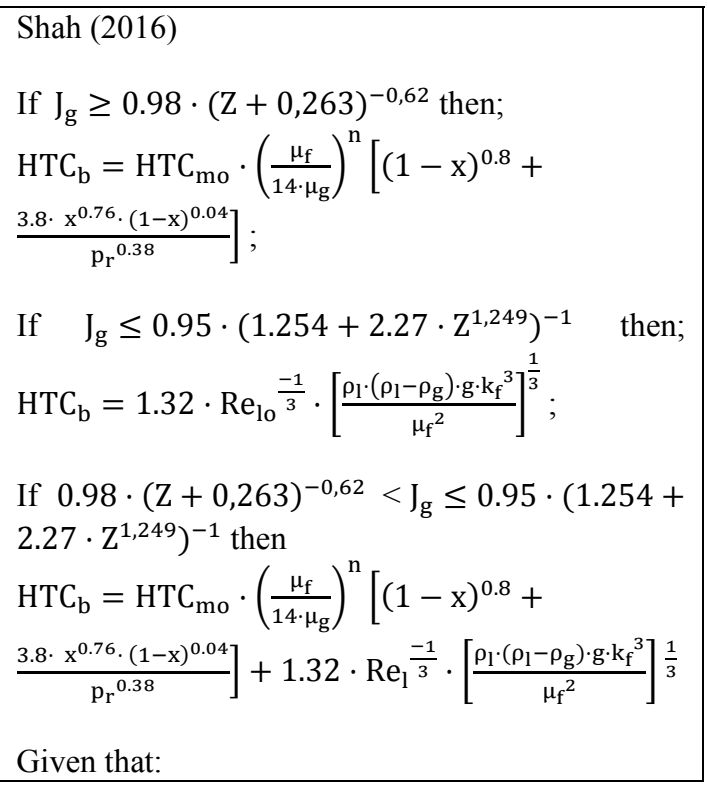




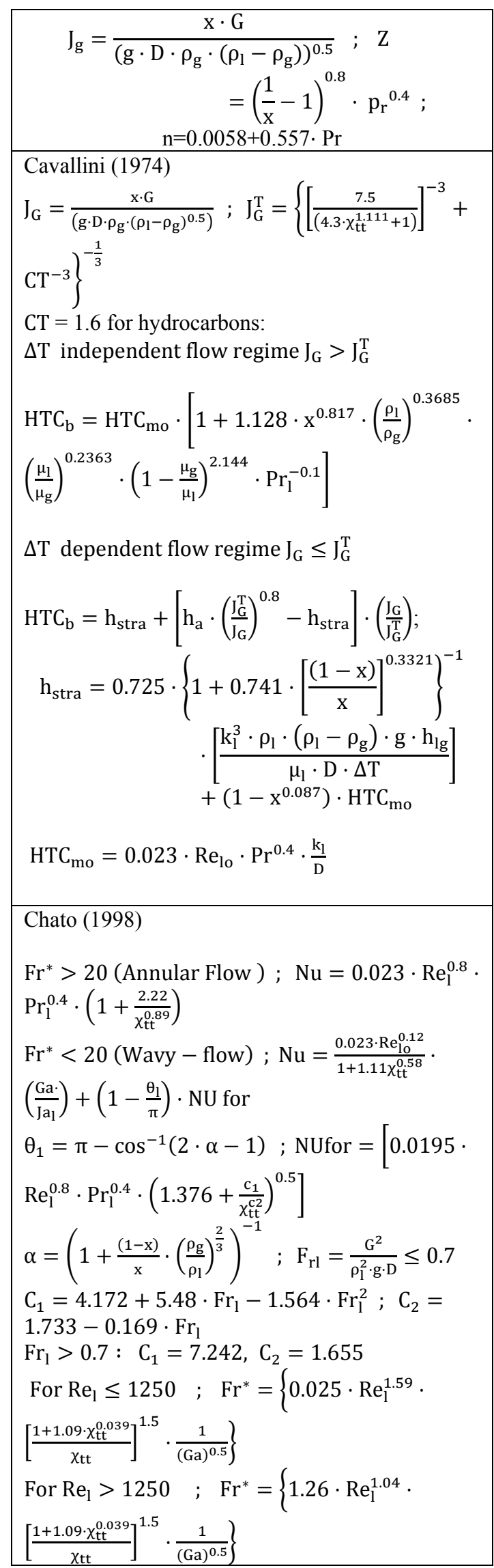

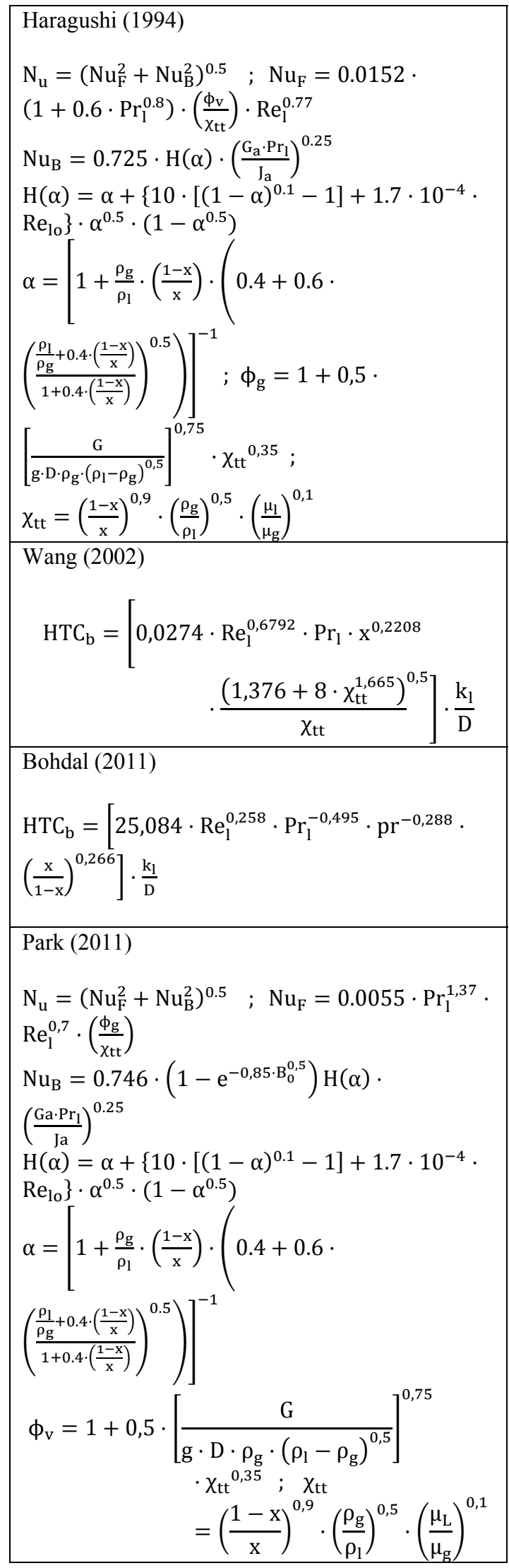




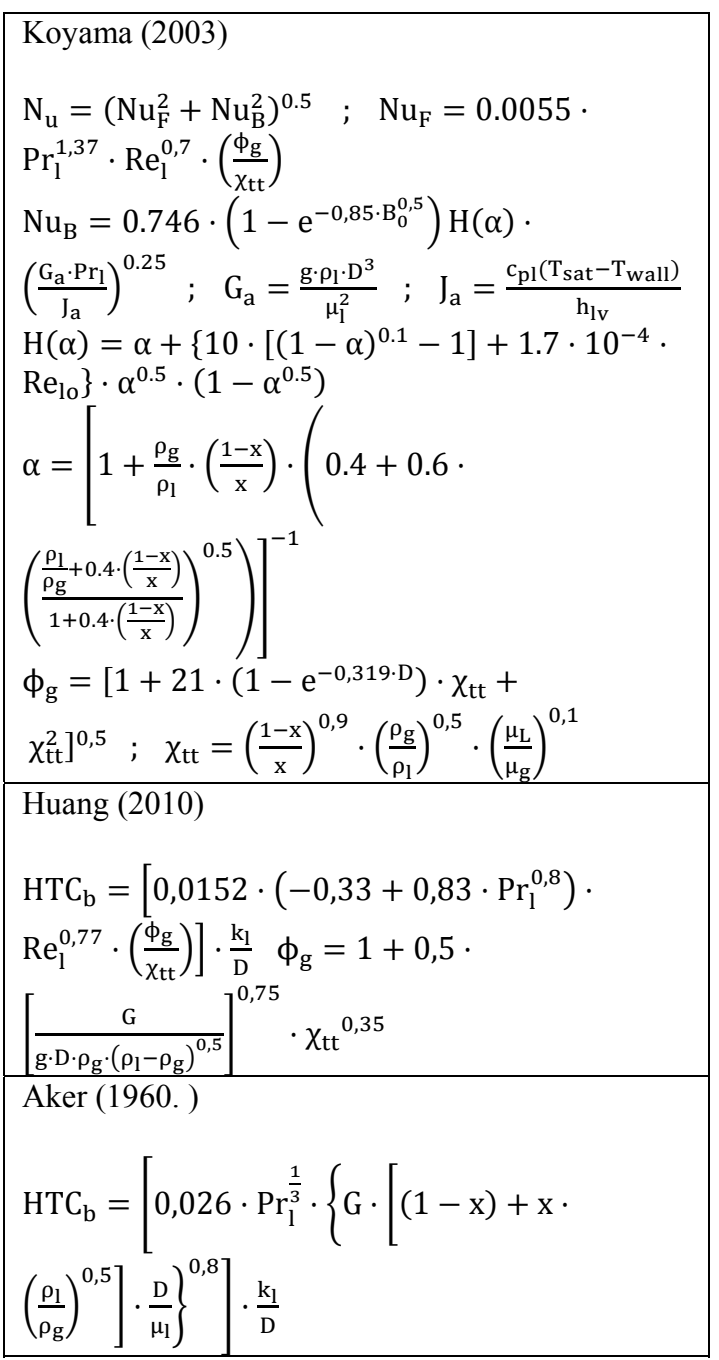

The predicted HTC given by each correlation above was then compared with experimental results through three mathematical parameters: The Mean Relative Deviation (MRD); Mean Absolute Relative Deviation (MARD) and accuracy, representing how many experimental data was encompassed within a $\pm 20 \%$ deviation of the predicted value given by each literature correlation, as follows:

$$
\begin{aligned}
& \text { MRD }=\frac{1}{n} \cdot \sum_{i=1}^{n} \frac{\mathrm{HTC}_{\text {pred }}(\mathrm{i})-\mathrm{HTC}_{\exp }(\mathrm{i})}{\mathrm{HTC}_{\exp }(\mathrm{i})} \\
& \text { MARD }=\frac{1}{\mathrm{n}} \cdot \sum_{\mathrm{i}=1}^{\mathrm{n}}\left|\frac{\mathrm{HTC}_{\text {pred }}(\mathrm{i})-\mathrm{HTC}_{\exp }(\mathrm{i})}{\mathrm{HTC}_{\exp }(\mathrm{i})}\right|
\end{aligned}
$$

Accuracy $=\mid 100 \%-$

(percentage of data outside $20 \%$ range)|

\section{RESULTS}

Figure 4 shows the graphs of evolution of the condensation heat transfer coefficient in terms of the quality of vapor for different mass flux and condensation temperatures for refrigerant R134a. The average expanded uncertainty of the coefficient was around $15 \%$. The R134a local condensation Heat Transfer coefficient were measured through an $4.8 \mathrm{~mm}$ internal diameter smooth horizontal aluminium pipe, across the entire quality range and mass flux varying between 200 and $300 \mathrm{~kg}\left(\mathrm{~m}^{2} \mathrm{~s}\right)^{-1}$, with $50 \mathrm{~kg}\left(\mathrm{~m}^{2} \mathrm{~s}\right)^{-1}$ steps.
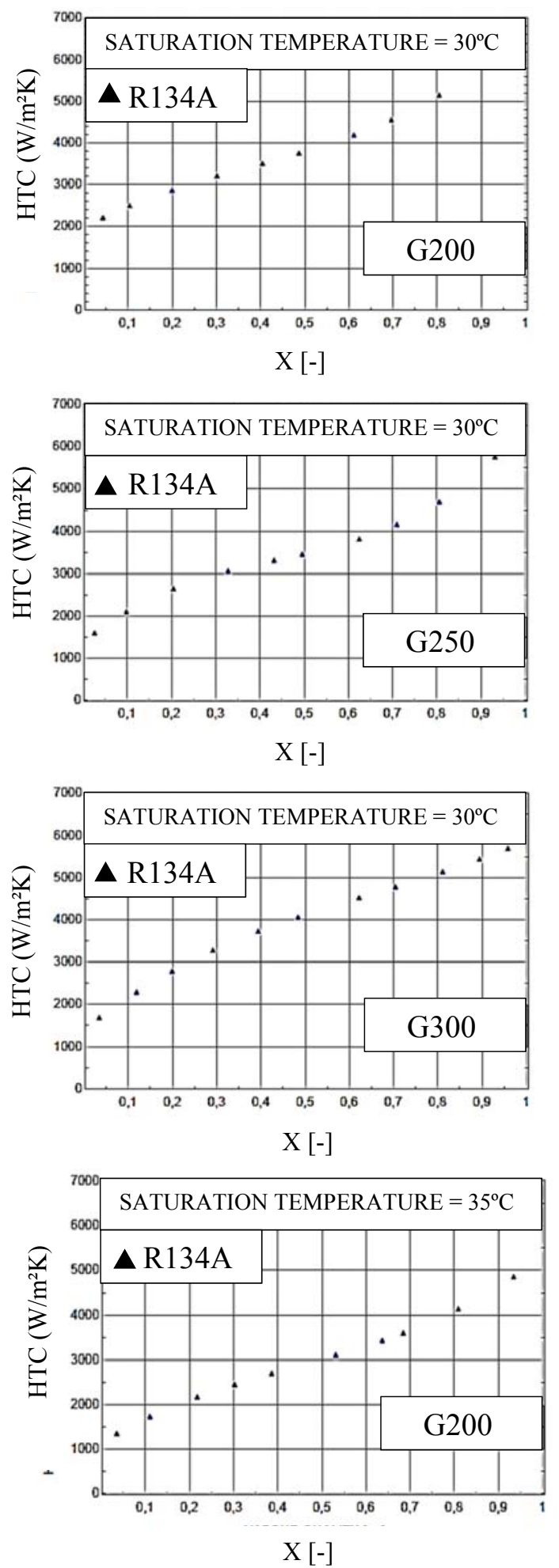

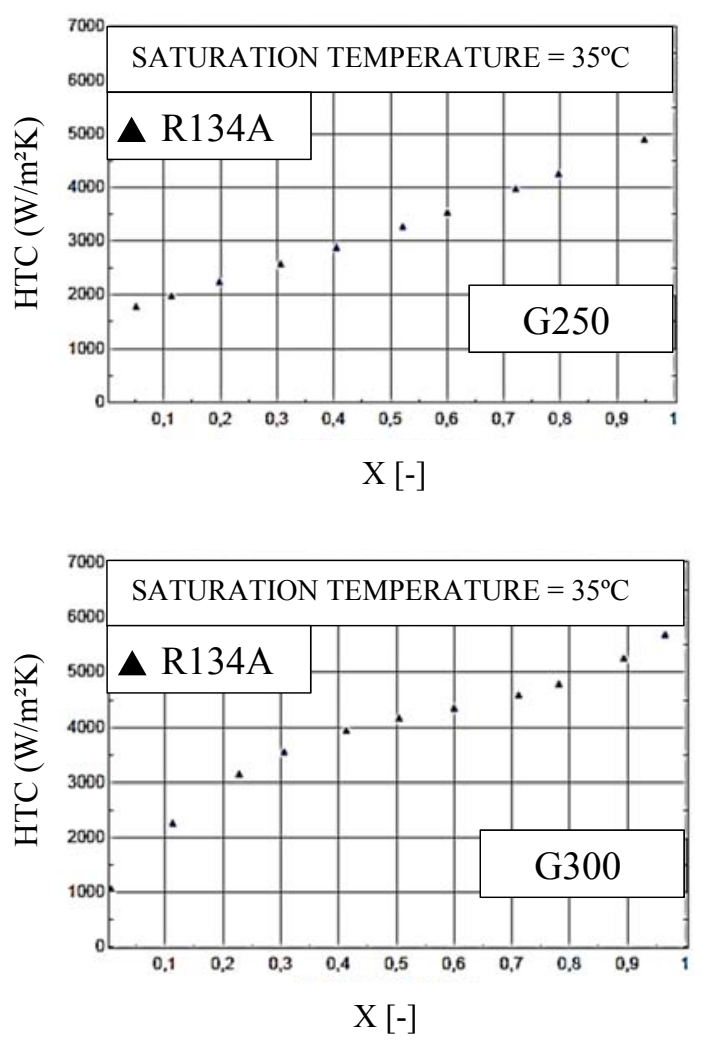

Figure 4. R134a local condensation Heat Transfer Coefficients at given conditions

Figure 4 depicts the change in R134a local condensation HTC as a function of vapour quality, mass flux $(G)$ and saturation temperature. The increase in HTC which accompanies the growing vapour quality is expected and confirmed in experimental results. This is because as the test section is increasingly filled with vapour rich two-phase mixture, the liquid phase film in contact with the tube's wall thickness decreases, and so does the thermal resistance. This leads to an overall increase in HTC and local condensation heat transfer. Furthermore, as more vapour is produced, the average mixture specific volume increases, and thus, to keep the total mass flux constant the gaseous phase relative to liquid flow velocity must increase. This leads to waves appearing in liquid-vapour interface layer, which themselves increase the total heat transfer available area and HTC. Conversely, when the vapour quality is low, the liquid layer is thicker and gravitational effects are predominant, resulting in a stratified flow, reducing heat transfer available area and, consequently, HTC.

Now, analysing the saturation temperature effect of the condensation HTC, higher temperatures result in smaller coefficients. This behaviour was observed across the entire quality and mass flux range. A higher temperature - and vapour pressure consequently - results in a significant increase in the vapour specific mass $\rho_{\mathrm{g}}$. Simultaneously, the specific mass of the vapour phase is considerably less affected by this pressure and temperature change, as volumetric dilation and contraction is not so effective. These two effects combined yield closer density figures in the two phases, which in turn, decreases the net shear effect due to the-phases velocity difference. As previously explained, this velocity difference induces turbulence in the fluid flow and the formation of waves, ultimately increasing the HTC. Finally, at higher mass flux rates, the shear effect caused by the flow velocity difference is increased, causing turbulence and larger HTC.

For comparison sake, the results published by Chang Yo (2009) were compared to the HTC found experimentally in this paper, at saturation temperatures equal to $40^{\circ} \mathrm{C}$ and mass flux levels of 200 and $300 \mathrm{~kg}\left(\mathrm{~m}^{2} \mathrm{~s}\right)^{-1}$. The results presented in Fig. (5) confirms that the values found in the reference are close to the ones obtained experimentally in the test rig at $35^{\circ} \mathrm{C}$.

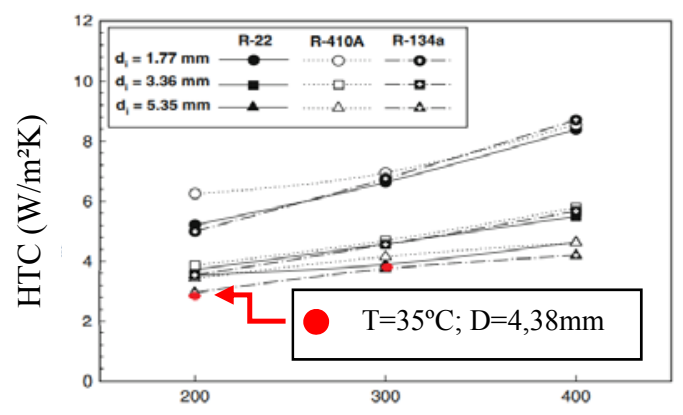

Figura 5. Comparison with Chang-Yo's work

In this paper, the coefficients were compared to literature references, namely Shah (2016), Cavallini (1974), Chato (1998), Aker (1960), Park (2011), Haragushi (1994), Koyama (2003), Wang (2002), Huang (2010) and Bohdal (2011). Equations (8) to (10) were used to compare the reference values to the experimental data. The Mean Relative Deviation, Mean Absolute Relative Deviation and Accuracy figures are presented in Tab. (4), following.

Tabela 4 - MRD, MARD and Accuracy Experimental x References

\begin{tabular}{|c|c|c|c|}
\hline CORRELATION & MRD & MARD & $\begin{array}{c}\text { ACCUR. } \\
(\%)\end{array}$ \\
\hline CHATO & -0.04 & 0.11 & 91.94 \\
\hline HARAGUSHI & -0.03 & 0.09 & 90.32 \\
\hline CAVALLINI & -0.20 & 0.20 & 54.84 \\
\hline BOHDAL & -0.18 & 0.19 & 50.00 \\
\hline HUANG & -0.29 & 0.30 & 40.32 \\
\hline KOYAMA & -0.24 & 0.25 & 30.65 \\
\hline WANG & -0.75 & 0.75 & 11.29 \\
\hline SHAH & -0.36 & 0.36 & 3.23 \\
\hline ARKER & -0.56 & 0.56 & 0.00 \\
\hline PARKER & -0.72 & 0.72 & 0.00 \\
\hline
\end{tabular}




\section{CONCLUSIONS}

This paper goal is to provide experimental values to the local condensation R134a HTC in a smooth, horizontal aluminium $4.8 \mathrm{~mm}$, aiming to increase the fluid information database. The Heat Transfer Coefficient was measured through an experimental setup, specifically built to this purpose, in three mass flux $\left(200,250\right.$ and $\left.300 \mathrm{~kg}\left(\mathrm{~m}^{2} \mathrm{~s}\right)^{-1}\right)$ and two saturation temperature levels ( 30 and $\left.35^{\circ} \mathrm{C}\right)$, across the entire unit vapour quality range. The experimental test section is composed of a $4.8 \mathrm{~mm}$ internal diameter, $75 \mathrm{~mm}$ external dimeter, $1000 \mathrm{~mm}$ length aluminium tube exchanging heat with cold water flowing in counter current. Temperature and pressure were measured in several location, enabling thus the thermodynamic characterisation under several flow and state regimes.

The results indicate a HTC increase for larger vapour quality levels. Conversely, higher saturation temperatures resulted in smaller Heat Transfer coefficients. At $30^{\circ} \mathrm{C}$ and mass velocities equal to 200,250 and $300 \mathrm{~kg}^{2}\left(\mathrm{~m}^{2} \mathrm{~s}\right)^{-1}$ the average condensation heat transfer coefficients found were equal to $3781, \quad 3459$ and $3944 \mathrm{~W}\left(\mathrm{~m}^{2} \mathrm{~K}\right)^{-1}$ respectively, whereas at $35^{\circ} \mathrm{C}$ the results for the same mass flux rates found equalled to 2904, 3141 and $3892 \mathrm{~W}\left(\mathrm{~m}^{2} \mathrm{~K}\right)^{-1}$.

The experimental data acquired in this paper were then compared to ten correlation commonly cited in reference literature. Mean Relative Deviation, Mean Absolute Relative Deviation and total accuracy were calculated for each reference, and Chato's correlation achieve the best fitting, with the statistical variables MRD, MRAD and Accuracy equal to - $0.04,0.11$ and 91.94\% respectively. Liekwise, Haragushi's also performed positively well, with presenting fitting values equal to $-0.03,0.09$ and $90.32 \%$.

\section{ACKNOWLEDGEMENTS}

The authors acknowledge with gratitude the support of the Capes and CNPQ.

\section{REFERÊNCIAS}

Barreda, N., Marvillet, Ch., Bontemps, A., Daoudi, S.,1996, Transferts de chaleur lors de la condensation du mélange HFC23/HFC134a à l'intérieur d'un tube lisse horizontal, International Journal of Refrigeration, vol. 19, $\mathrm{n}^{\mathrm{o}}$ 7, pp. 463-472.

Sapali, S. N. and Patil, P. A., 2009, Heat transfer during condensation of HFC-134a and R-404A inside of ahorizontal smooth and micro-fin tube, Experimental Thermal and Fluid Science, vol. 34, pp. 1133-1141.

Micropump., 2016, GJ Series Datasheet, Vancouver.
Taylor, J. R., 1997, Introduction to Error Analysis: The Study of Uncertainties in Physical Measurements, University Science Books, $2^{\text {nd }}$ ed.

Shah, M. M., 2016, A correlation for heat transfer during condensation in horizontal mini/micro channels, International Journal of Refrigeration, Vol. 64, pp. 187-202.

Cavallini, A., Zecchin, R., 1974, A dimensionless correlation for heat transfer in forced convection condensation, Proc. Fifth Int. Heat Transfer Conf, Vol. 3, pp. 309-313.

Dobson, M. K., Chato, J. C., 1998, Condensation in smooth horizontal tubes, ASME J.Heat Transfer, Vol. 120, pp. 193-213.

Haraguchi, H., Koyama, S., Fujii, T., 1994, Condensation of refrigerants HCFC 22, HFC134a and HCFC 123 in a horizontal smooth tube, $\left(2^{\text {nd }}\right.$ report, rans. JSME, pp. 245-252.

Akers, H. R. W.W., 1960, Condensation inside a horizontal tube, Chem. Eng., Vol. 56, pp. 145149.

Bohdal, S. T., Charun, H., Sikora, M., 2011, Comparative investigations of the condensation of $\mathrm{R} 134 \mathrm{a}$ and $\mathrm{R} 404 \mathrm{~A}$ refrigerants in pipe minichannels, Int. J.Heat Mass Transfer, Vol. 54, pp. 1963-1974.

Park, J. E., Vakili-Farajani, F., Consolini, L., Thome., J. R., 2011, Experimental study on condensation heat transfer in vertical minichannels for new refrigerant R1234ze (E) versus R134a and R236fa," Exp. Therm. Fluid Sci., Vol. 35, pp. 442454.

Wang, W. W., Redeliff, T. D., Christensen, R. N., 2002, Condensation heat transfer correlation for millimeter-scale tubing with flow regime transition, Exp.Therm. Fluid Sci, Vol. 26, pp. 473-485.

Huang, X., Dining, G., Hu, H., Zhu, Y., Peng, H., Gao, Y., Deng, B., 2010, Influence of oil on flow condensation heat transfer of R410A inside $4.18 \mathrm{~mm}$ and $1.6 \mathrm{~mm}$ inner diameter horizontal smooth tubes, Int. J. Refrigeration, Vol. 33, pp. 158-169.

Koyama, S., Kuwahara, K., Nakashita., Kouichi, N., Yamamoto, K., 2003, An experimental study on condensation of refrigerant R134a in a multi-port extruded tube, Int. J. Refrigeration, Vol. 24, pp. 425-432.

H. Haraguchi, 1994, Condensation of refrigerants hcfc22, hfc134a and hcfc123 in a horizontal smooth tube (2nd report, Trans. JSME,(B), pp. 239-244.

Son, C., Lee, H., , 2009, Condensation heat transfer characteristics of R-22, R-134a and R-410A in small diameter tubes, Heat And Mass Transfer, pp. 1153-1166. 